\title{
Optimalisasi Upaya Penerapan Lean Hospital di Unit Rawat Jalan Rumah Sakit Tugu Ibu Depok
}

\section{Optimizing the Efforts in Implementing 'Lean Hospital' at the Outpatient Unit of Tugu Ibu Hospital Depok}

\author{
Ayu Muthia ${ }^{1}$, Ratna Atina Riandhini ${ }^{2}$, Angsur Sudirja ${ }^{3}$ \\ ${ }^{123}$ Institut Kesehatan Indonesia (IKK) Jakarta \\ Email: ayumufua@gmail.com; ratna.riandhini@yahoo.com; \\ angsur78.sudirja@gmail.com
}

\begin{abstract}
ABSTRAK
Penelitian ini bertujuan untuk menganalisis penerapan Lean Hospital di unit rawat jalan Rumah Sakit Tugu Ibu Depok. Dilakukan penelitian kualitatif mengenai gambaran alur proses kondisi saat ini di unit rawat jalan Rumah Sakit Tugu Ibu Depok, mengidentifikasi aktivitas dalam proses kerja di unit rawat jalan, dan menganalisa Value Stream Map unit rawat jalan. Berdasarkan hasil penelitian dapat disimpulkan bahwa hasil Value Assessment pasien mulai dari proses pendaftaran hingga mendapatkan obat di apotik masih menunjukan wasting time yang terlalu lama, hal ini karena banyaknya hambatanhambatan yang terjadi sepanjang alur proses pelayanan unit rawat jalan. Hasil identifikasi kegiatan dan aktivitas selama proses kerja unit rawat jalan yang ada banyak ditemukan pemborosan (Waste), sehingga rasio aktivitas yang bernilai tambah (Value Added Activities) ada yang kurang dari 30\%, sebagai bentuk masalah berada pada manusia / man, method, machine serta environment. Usulan perbaikan dilakukan dengan menganalisis akar penyebab masalah, membuat langkah-langkah perbaikan dengan memperkirakan kemampuan rumah sakit dan faktor-faktor yang mempengaruhinya.
\end{abstract}

Kata Kunci : Optimalisasi, Penerapan Lean, Lean Hospital

\begin{abstract}
This research aims to analyze the implementation of Lean Hospital in the Outpatient Unit of Tugu Ibu Hospital Depok. This is a qualitative type of research which describes the current condition of the service process flow in the Outpatient Unit of Tugu Ibu Hospital Depok. It also identifies the working activities and analyzes the Value Stream Map of the Outpatient Unit. Based on the research results, it is concluded that the Value Assessment engaged with patients, starting from the registration process till obtaining the medications at pharmacies, still indicates a long wasting time. This is arised due to many obstacles occurred throughout the flow of the service process in the Outpatient Unit. The identification of activities during the working process in the Outpatient Unit also shows a waste in time, thus the ratio of Value Added Activities is less than 30\%, with most of the problems emerging from the workers, methods, machines, as well as the environment. The improvements suggested include analyzing the root of the problems, and managing some corrective moves by estimating the hospital abilities and the influencing factors.
\end{abstract}

Keywords: Optimizing, Implementation of the Lean, Lean Hospital 


\section{PENDAHULUAN}

Rumah sakit memberikan berbagi layanan kesehatan, salah satu pelayanannya berupa rawat jalan. Rawat jalan adalah pelayanan medis kepada seorang pasien untuk tujuan pengamatan, diagnosis, pengobatan, rehabilitasi dan pelayanan kesehatan lainnya tanpa mengharuskan pasien tersebut dirawat inap. Pelayanan rawat jalan merupakan salah satu andalan bagi rumah sakit dalam meningkatkan pemasukan dan penunjang bagi unit lainnya. Salah satu konsep yang dapat digunakan untuk memberikan pelayanan yang memuaskan serta efisiensi biaya adalah mengaplikasikan konsep Lean dalam pelayanan kesehatan.(Lash, 2009) Meminimalisasi waste, yang biasa disebut pemborosan dalam pelayanan kesehatan ditentukan pada output dan flow. Output yang dimaksud ialah proses yang salah, seperti overproduction, sedangkan flow adalah waktu tunggu, duplikasi dalam proses ataupun proses yang diulang. Salah satu konsep yang dapat digunakan adalah dengan Lean Hospital, dengan pengertian pendekatan yang sistematis untuk mengidentifikasi dan menghilangkan pemborosan (waste) atau dengan aktifitas yang tidak bernilai tambah (non value adding activities) melalui peningkatan terus menerus (continous improvement) dengan cara mengalirkan produk (material, process, output) serta informasi system tarik (pull system) dari pelanggan internal dan eksternal untuk mengejar keunggulan dan kesempurnaan. (Gaspersz, 2011) (Hines et al., 2004).

Sejumlah bukti empiris telah dikemukakan terkait manfaat Lean di rumah sakit. Vliet et al (2010) melakukan studi pada The Cataract Clinic, The Rotterdam Eye Hospital, bahwa dengan metode ini dapat menurunkan jumlah pasien rawat jalan berulang sebesar $23 \%$ dan meningkatkan akses pasien sebanyak $42 \%$. ("Lean and Six Sigma: A practical guide for clinicians and managers," 2010) Dari sisi penghematan biaya, penerapan Lean di Nationwide Children's Hospital menghemat biaya obat $\$ 8.197$ per- minggu dan pembelian obat menurun hingga 2,6\% per tahun. (L'Hommedieu \& Kappeler, 2010) Terkait hubungan Lean dengan penghematan waktu pelayanan diberikan oleh studi yang dilaporkan oleh Tanninecz, bahwa waktu layanan emergency mengalami percepatan di Hotel-Dieu Grace Hospital Windsor Ontario, Kanada. Ada tiga percobaan yang dilakukan, 
Ayu Muthia, Ratna Atina Riandhini, Angsur Sudirja : Optimalisasi Upaya ...

hasil yang pertama dari 120 menit menjadi 30 menit, hasil kedua 103 menit menjadi 54 menit dan percobaan ketiga memberikan penghematan waktu dari 94 menit menjadi 49 menit. (Ben-Tovim et al., 2007) Aspek efisiensi kerja juga dapat diperbaiki menggunakan praktik Lean. Studi Rutledge et al menemukan bahwa pemeriksaan di laboratorium urine di USA menjadi 111 kaki dari yang sebelumnya 218 kaki dan Virginia Mason Medical Center di Seatle, Washington mereduksi 35-50\% area kerja. (Astion et al., 2012) Menurut penelitian yang dilakukan oleh Direktur Umum RSIA Kemang, dr. A. Heri Iswanto, Lean di rumah sakit tersebut meningkatkan indeks kepuasan pelanggan sebesar $11 \%$ dari $76 \%$ menjadi 87\%. Pasien puas terutama dalam hal tangible/wujud dan Emphaty/empati. Pasien merasakan dampak langsung dari sistem manajemen ini di rumah sakit. (Iswanto, 2015).

Rumah Sakit Tugu Ibu Depok telah berusaha untuk memberikan pelayanan yang bermutu pada unit rawat jalan ini, namun dengan adanya keluhan pasien terhadap proses pelayanan, diantaranya dokter yang datang tidak tepat waktu, rekam medis yang terlambat atau terselip, jarak laboratorium yang cukup jauh, maka peneliti perlu mengetahui proses pelayanan dari sudut pandang pasien. Selain itu dari observasi yang dilakukan oleh peneliti ditemukan adanya sistem dan prosedur yang belum efisien dari alur proses di rawat jalan. Dalam rangka meningkatkan mutu pelayanan kepada pasien dimungkinkan untuk memperbaiki alur proses dan mengatasi permasalahan yang mengakibatkan waktu pelayanan yang lama di unit rawat jalan. Penelitian ini dilakukan untuk mengidentifikasi permasalahan yang terkait dengan alur proses pelayanan unit rawat jalan Rumah Sakit Tugu Ibu Depok, membuat gambaran terhadap proses pelayanan dan komponen yang mendukung, manusia, peralatan yang digunakan, metode kerja serta aspek lingkungan fisik. Hasilnya akan dianalisis untuk dilakukan perbaikan pada alur proses pelayanan.

\section{METODE}

Penelitian ini bersifat studi kasus dengan pendekatan kualitatif melalui observasi dan telaah data dari rumah sakit serta proses pelayanan dan wawancara dengan pejabat departemen rawat jalan Rumah Sakit Tugu Ibu Depok. Data 
berasal dari data primer dan sekunder. Data primer diperoleh dari observasi langsung terhadap proses pelayanan di unit rawat jalan Rumah Sakit Tugu Ibu Depok dan wawancara tidak tersruktur, dengan informan sebanyak 10 orang terdiri dari Manajer Rumah Sakit, Kepala Unit Rawat Jalan, Dokter, Perawat, Administrasi, Rekam Medik, Apotik dan Pasien, serta wawancara mendalam dengan informan terpilih. Informan tersebut dianggap akan memberikan informasi secara cukup dan sesuai dengan kebutuhan peneliti. Hasil dari wawancara tersebut akan diteliti kembali melalui observasi kembali dengan tujuan apakah sudah sesuai dengan yang terjadi di lapangan sebenarnya ataupun dapat melakukan koreksi data yang kurang sesuai jika ditemukan. Sedangkan data sekunder diperoleh dari hasil pencatatan unit terkait dan telaah dokumen.

Metode dan teknik pengumpulan data yang dilakukan dalam penelitian ini adalah Observasi Parsitipatif, wawancara dan telaah dokumen. Peneliti mengamati apa yang dikerjakan orang lain, mendengarkan apa yang diucapkan dan berpartisipasi dalam aktivitas yang diteliti. (Stainback \& Stainback, 1984) Sedangkan berdasarkan klasifikasinya pada penelitian ini adalah termasuk partisipasi pasif, karena peneliti mengamati tetapi tidak terlibat dalam kegiatan tersebut. (Faisal, 1990) Wawancara dilakukan terhadap informan terpilih yang dianggap mengetahui obyek yang akan dilakukan penelitian. Informan ini akan diminta pendapat dan informasinya dengan diajak melihat dari sudut pandang pasien.

Hasil wawancara dengan informan tersebut digunakan sebagai data pendukung terhadap hasil observasi. Telaah dokumen dilakukan dengan cara pencatatan tehadap data-data pendukung yang diperlukan. Data ini disebut juga data sekunder yang meliputi alur proses pasien, arsip standar pelayanan, denah rawat jalan dan data lain yang ada di Rumah Sakit Tugu Ibu Depok khususnya yang terkait dengan penelitian. Instrumen pengumpulan data yang digunakan pada penelitian ini adalah pedoman observasi dan wawancara yang berisi pertanyaan yang diajukan kepada informan terpilih. Pedoman observasi berisi panduan pengamatan di unit rawat jalan dan checklist dokumen sebagai panduan proses menelaah dokumen. Selain itu ada instrumen tata letak yang dimulai dengan 
Ayu Muthia, Ratna Atina Riandhini, Angsur Sudirja : Optimalisasi Upaya ...

mengidentifikasi permasalahan, pemborosan dan analisis akan masalah sampai dengan dikelompokkan dalam system pelayanan rawat jalan secara keseluruhan. Dalam penelitian ini, untuk menjaga validitas digunakan adalah triangulasi sumber data untuk pengecekan terhadap konsistensi informasi yang didapat dari sumber yang berbeda dan triangulasi metode. yang dilakukan apabila penelitian menggunakan lebih dari satu metode pengumpulan data. Data diperoleh dari telaah dokumen, wawancara dan observasi (Triagulasi).

\section{HASIL}

Alur pasien digambarkan dengan menggunakan diagram spaghetti, yaitu sebuah bantuan grafis yang digunakan untuk membantu dalam penciptaan praktek produksi yang efisien dengan menggambarkan gerakan fisik dan jarak yang terlibat dalam sebuah proses. Dalam proses pelayanan rawat jalan di Rumah Sakit Tugu Ibu Depok dapat dilihat dalam diagram berikut :

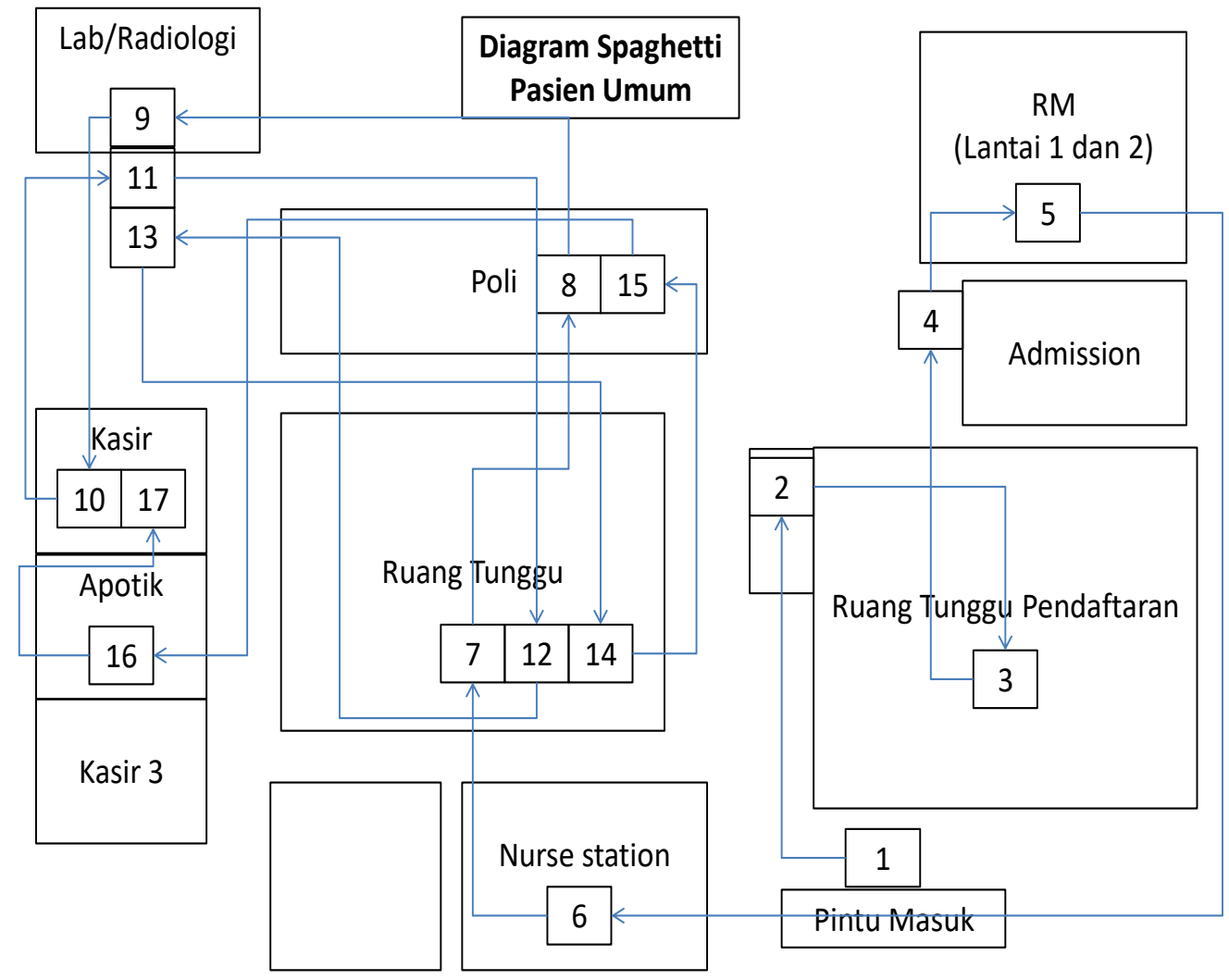

Gambar 1. Diagram Spaghetti Alur Pasien Umum 
Pada pasien umum, pasien masuk (1) dan langsung mengambil nomor antrian (2), lalu menunggu di ruang tunggu (3) sampai nomor antrian dipanggil oleh admission (4). Di admission pasien umum hanya menyerahkan kartu berobat. Admission akan melakukan input data dan bagian Rekam Medik (5) akan mencari Rekam Medik pasien. Setelah Rekam Medik didapatkan, maka petugas Rekam Medik akan mengantarkan rekam medis ke nurse station (6) yang kemudian dipilih oleh perawat untuk dibawa ke poliklinik tujuan. Selanjutnya, pasien akan menunggu hingga namanya dipanggil untuk diperiksa (7), perawat akan memanggil nama pasien sesuai dengan nomor urut saat melakukan pendaftaran dan pasien akan diperiksa oleh dokter (8). Apabila diperlukan untuk dilakukan pemeriksaan penunjang, maka dokter akan memberikan form yang harus diserahkan ke laboratorium atau radiologi yang letaknya agak jauh dari poliklinik (9), setelah menyerahkan form maka pasien akan diarahkan untuk melakukan pembayaran di kasir (10) yang letaknya lebih dekat dengan poliklinik dan cukup jauh dari laboratorium dan radiologi tersebut. Setelah melakukan pembayaran maka pasien akan ke laboratorium atau radiologi tadi untuk dilakukan pemeriksaan (11). Setelah itu pasien akan menunggu kembali (12). Bila memungkinkan pemeriksaan dianalisa hari itu, maka pasien akan mengambil hasil (13), lalu menunggu di depan poliklinik tadi untuk menyerahkan hasil kepada dokter (14). Perawat akan mempersilakan pasien selanjutnya yang menunggu di poliklinik terlebih dahulu baru mempersilakan pasien tersebut bertemu dengan dokter (15). Dokter akan memberikan resep untuk selanjutnya diambil di apotik (16), lalu pasien akan membayar di kasir (17) lalu menunggu kembali untuk mendapatkan obat. 


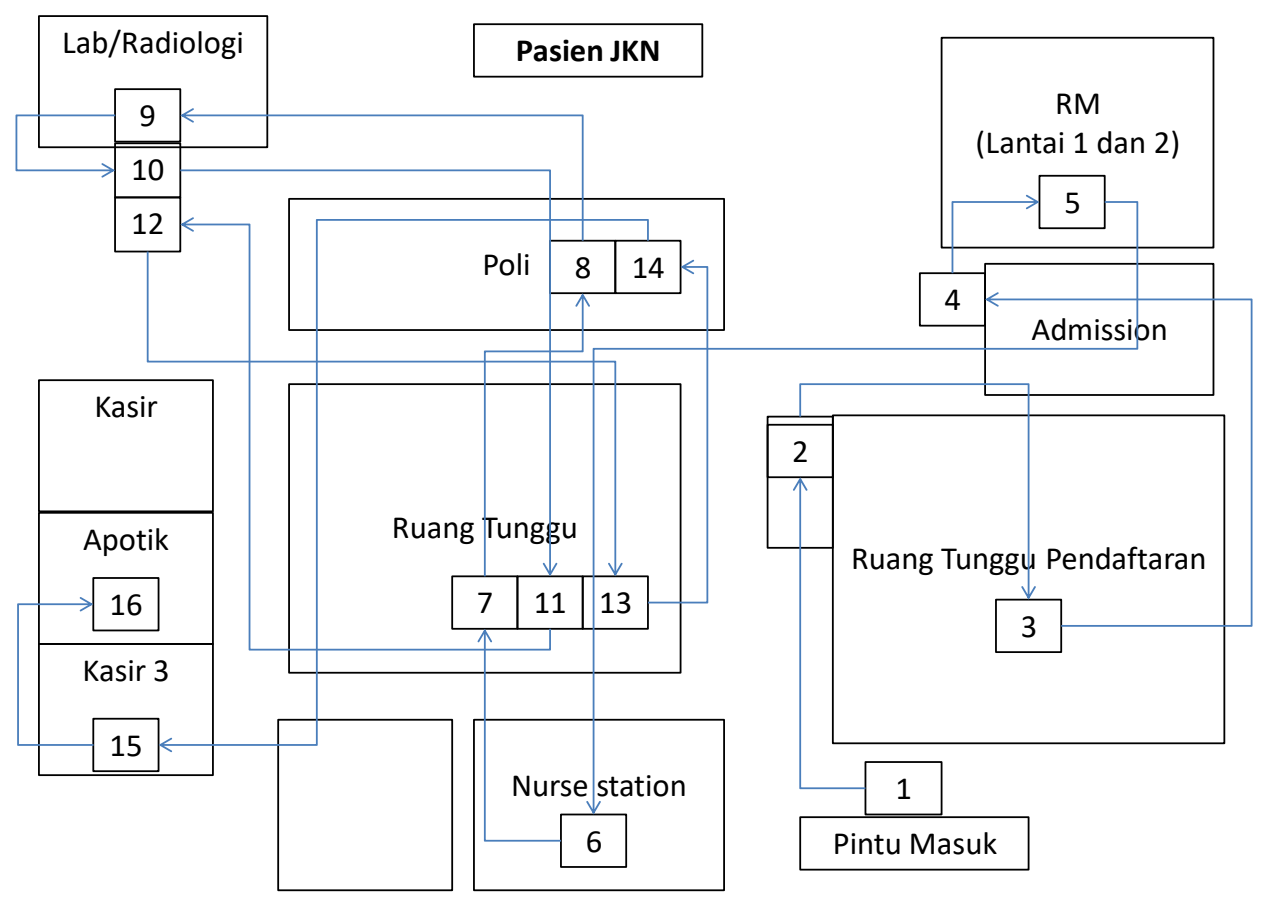

Gambar 2 Diagram Spaghetti Alur JKN

Pada pasien JKN, pasien masuk (1) dan langsung mengambil nomor antrian (2), lalu menunggu di ruang tunggu (3) sampai nomor antrian dipanggil oleh admission (4). Di admission pasien JKN menyerahkan surat rujukan, fotokopi KTP, fotokopi KK (untuk pasien anak), dan fotokopi kartu peserta JKN/BPJS. Admission akan melakukan input data, menyerahkan SEP dan surat pengantar jaminan kepada pasien. Bagian rekam medik (5) akan mencari Rekam Medik pasien. Setelah Rekam Medik didapatkan, maka petugas Rekam Medik akan mengantarkan rekam medis ke nurse station (6) yang kemudian dipilih oleh perawat untuk dibawa ke poliklinik tujuan. Selanjutnya, pasien akan menunggu hingga namanya dipanggil untuk diperiksa (7), perawat akan memanggil nama pasien sesuai dengan nomor urut saat melakukan pendaftaran dan pasien akan diperiksa oleh dokter (8). Apabila diperlukan untuk dilakukan pemeriksaan penunjang, maka dokter akan memberikan form yang harus diserahkan ke laboratorium atau radiologi yang letaknya agak jauh dari poliklinik (9), dan pasien dapat langsung melakukan pemeriksaan. (10). Setelah itu pasien akan menunggu kembali (11). Bila memungkinkan pemeriksaan dianalisa hari itu, maka pasien 
akan mengambil hasil (12), lalu menunggu di depan poliklinik tadi untuk menyerahkan hasil kepada dokter (13). Perawat akan mempersilakan pasien selanjutnya yang menunggu di poliklinik terlebih dahulu baru mempersilakan pasien tersebut bertemu dengan dokter (14). Dokter akan memberikan resep untuk selanjutnya pasien akan diminta untuk ke kasir 3 untuk memastikan apakah ada obat yang perlu dibayar atau tidak (15). Setelah itu pasien akan menunggu dan mengambil obat di apotik (16).

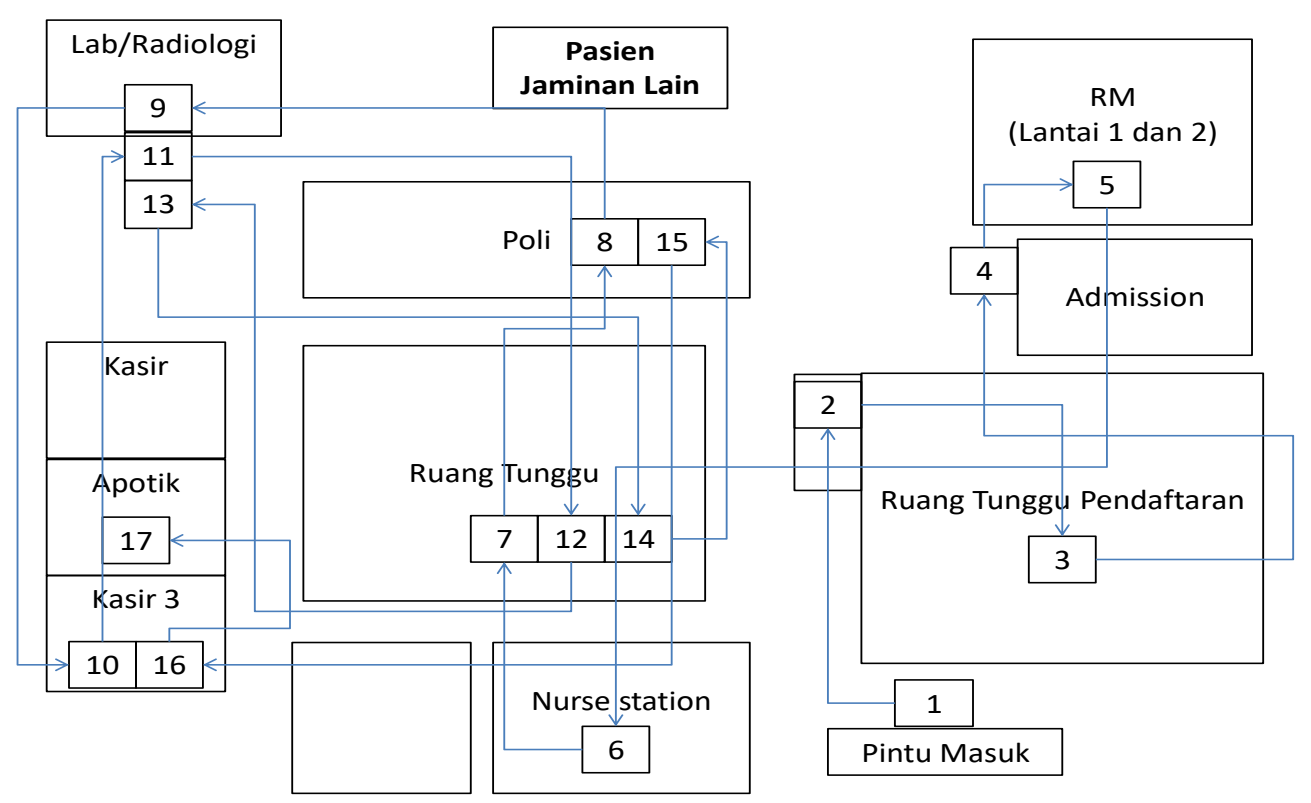

Gambar 3 Diagram Spaghetti Alur Jaminan Lain

Pada pasien Jaminan Lain, pasien masuk (1) dan langsung mengambil nomor antrian (2), lalu menunggu di ruang tunggu (3) sampai nomor antrian dipanggil oleh admission (4). Di admission pasien jaminan lain akan menyerahkan kartu asuransi atau jaminan lain dan melakukan swipe card. Admission akan melakukan input data dan bagian rekam medik (5) akan mencari Rekam Medik pasien. Setelah Rekam Medik didapatkan, maka petugas Rekam Medik akan mengantarkan rekam medis ke nurse station (6) yang kemudian dipilih oleh perawat untuk dibawa ke poliklinik tujuan. Selanjutnya, pasien akan menunggu hingga namanya dipanggil untuk diperiksa (7), perawat akan memanggil nama pasien sesuai dengan nomor urut saat melakukan pendaftaran 
Ayu Muthia, Ratna Atina Riandhini, Angsur Sudirja : Optimalisasi Upaya ...

dan pasien akan diperiksa oleh dokter (8). Apabila diperlukan untuk dilakukan pemeriksaan penunjang, maka dokter akan memberikan form yang harus diserahkan ke laboratorium atau radiologi yang letaknya agak jauh dari poliklinik (9), dan pasien diminta ke kasir 3 untuk memastikan apakah pemeriksaan ditanggung oleh pihak asuransi (10). Setelah itu pasien akan melakukan pemeriksaan. (11). Setelah itu pasien akan menunggu kembali (12). Bila memungkinkan pemeriksaan dianalisa hari itu, maka pasien akan mengambil hasil (13), lalu menunggu di depan poliklinik tadi untuk menyerahkan hasil kepada dokter (14). Perawat akan mempersilakan pasien selanjutnya yang menunggu di poliklinik terlebih dahulu baru mempersilakan pasien tersebut bertemu dengan dokter (15). Dokter akan memberikan resep untuk selanjutnya pasien akan diminta untuk ke kasir 3 untuk memastikan apakah ada obat yang perlu dibayar atau tidak (16). Setelah itu pasien akan menunggu dan mengambil obat di apotik (17).

\section{Identifikasi Waste}

Waste yang terjadi selama proses pelayanan Rawat Jalan dikelompokkan berdasarkan tanggung jawab setiap bagian yang terlibat dalam proses tersebut, yaitu bagian Admission, rekam medik, poliklinik, laboratorium, radiologi, apotik, dan kasir di bagian rawat jalan. Langkah pertama dalam mengidentifikasi waste yang menjadi masalah utama dalam konsep lean adalah dengan mengurai hasil observasi lapangan dan membandingkan flowchart dari data yang ditemukan di Rumah Sakit dengan keadaan sebenarnya terjadi. Langkah selanjutnya dilakukan dengan menganalisis hasil dari assessment non value added yang teridentifikasi waste untuk mencari akar masalah. Waste di Bagian Admission untuk pasien umum, jaminan dan JKN yang sering berobat tidak menjadi kendala, tapi jika pasien baru maka akan kesulitan untuk mengetahui proses pelayanannya, karena tidak ada costumer service, juga tidak ada petugas yang mengarahkan pasien, maupun banner / petunjuk / informasi cara pendaftarannya. Bila tidak ada antrian, pasien bisa langsung bertanya pada petugas admission, tapi bila antrian panjang pasien akan bertanya kepada sesama pasien. Belum ada standar baku dari admission mengenai surat control expired dan berkas surat pengantar jaminan, 
surat eligibilitas kepesertaan (SEP) dan nomor antrian pasien dibawa-bawa oleh pasien. Ruangan baru khusus pasien JKN belum berfungsi dengan optimal. Rumah Sakit Tugu Ibu Depok belum memiliki sistem antrian digital sehingga petugas harus berteriak memanggil nomor antrian dan pasien tidak terlalu dapat mendengar dengan jelas angka yang disebutkan apabila kondisi sedang ramai dikarenakan bising.

Setelah petugas pendaftaran mencatat kartu pasien, nomor tracer akan dicetak. Namun ditemukan bahwa petugas masih mengalami kesulitan dalam mencari rekam medik Waste yang terjadi antara lain penomoran tidak dibedakan antara status untuk pasien umum, pasien jaminan dan jaminan kesehatan nasional sehingga hal ini menyulitkan dalam mencari status pasien karena petugas hanya mencari berdasarkan nomor status saja. Dalam mencari rekam medik pasien, Rekam Medik yang diletakkan dibagian atas akan lebih sulit dalam pencarian dan pengambilan status. Petugas dalam mengambil status akan melemparkan status ke bawah/lantai sehingga map status pasien kemungkinan lebih mudah rusak. Jumlah pasien tidak sebanding dengan kecepatan petugas mencari Rekam Medik, sehingga Rekam Medik hingga jam 8.30 belum didistribusikan ke ruangan/poliklinik. Analisa: Penomoran, pewarnaan dan bentuk map rekam medik yang sedemikian rupa, letak rak penyimpanan berkas rekam medik yang sulit dijangkau menyebabkan waktu pengambilan map rekam medik petugas sulit mencarinya, untuk mempersingkat waktu petugas membuat status sementara (namun dengan nomor rekam medik yang sama). Petugas rekam medik tidak dapat mengetahui berkas rekam medik yang isinya telah lebih dari lima tahun tanpa harus membuka mapnya. Tidak dapat membedakan map rekam medik apakah milik pasien asuransi, JKN dan pasien umum.Fokus pengamatan terbatas pada kegiatan pasien selama alur proses rawat jalan dimulai dari pasien melakukan pendaftaran hingga prosses penerimaan obat di apotik. 


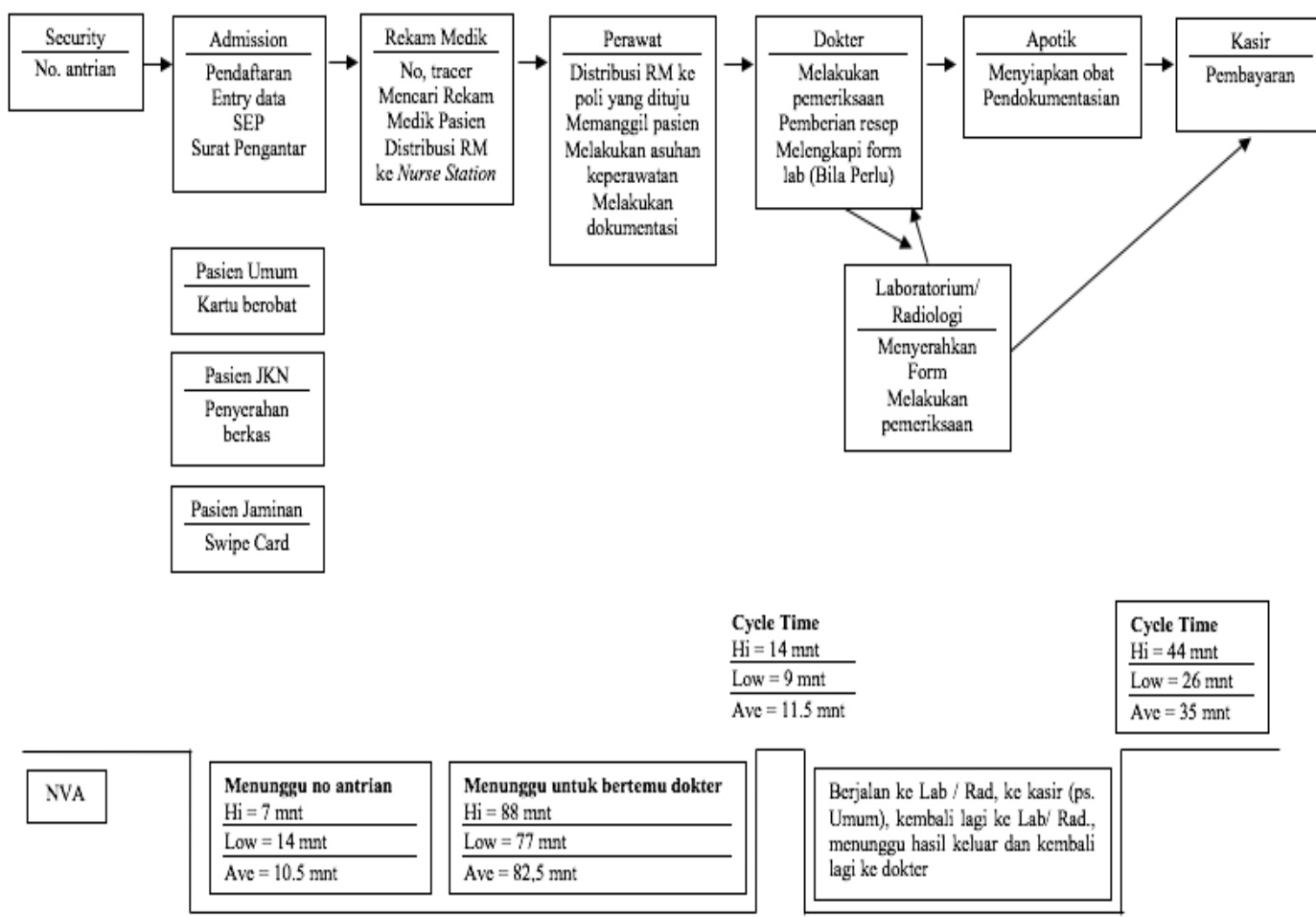

Gambar 4 Value Stream Map

\section{Desain Usulan Jangka Pendek ( 1 bulan - 6 bulan)}

Peningkatan kompetensi tenaga rekam medis : Ada 10 petugas yang ada di rekam medis dan hanya 3 diantaranya yang lulusan D3 Rekam medis. Sisanya masih lulusan SLTA sehingga paling tidak sangat membutuhkan pelatihan internal. Peningkatan kualitas SDM dengan adanya pelatihan dan pembelajaran mengenai service excellent juga diperlukan. Sesuai dengan konsep Lean yaitu kemauan untuk memperbaiki diri baik perorangan maupun kelompok untuk memperbaiki dan meningkatkan pengetahuan agar komunikasi bisa berjalan dengan baik dan pelayanan pun semakin meningkat. Memaksimalkan ruangan khusus JKN untuk mempermudah proses pendaftaran. Dengan adanya ruang khusus untuk pelayanan dan dengan fasilitas yang sudah disediakan oleh RS, diharapkan dapat meningkatkan pelayanan terhadap pasien khususnya pasien JKN. 
Meninjau kembali untuk bagian admission bekerjasama dengan BPJS untuk membuat program baku bagi pasien JKN khususnya yang surat kontrolnya mengalami expired date. Meninjau kembali SOP dan uraian tugas dari bagian keuangan dan kasir sehingga tidak perlu lagi ada "titipan" berkas yang harus ditandatangani oleh dokter. Mengoptimalkan buku inventaris dan penyediaan log book untuk menunjang pemantauan maintenance peralatan. Bekerjasama dengan pihak ketiga untuk perbaikan system swipe card melalui mesin EDC. Menyederhanakan Alur Proses Pelayanan Rawat Jalan.

Pada flowchart sebelumnya pasien umum yang menjalani pemeriksaan laboratorium atau radiologi menuju ke ruang penunjang untuk menyerahkan berkas dan form yang diperlukan, lalu dilakukan pembayaran ke kasir terlebih dahulu untuk membayar biaya pemeriksaan penunjang, lalu kembali lagi ke tempat pemeriksaan penunjang untuk melakukan pemeriksaan setelah menyerahkan bukti pembayaran, lalu menunggu sampai dengan hasil penunjang tersebut keluar, lalu kembali lagi ke dokter dan mengantri 1 nomor untuk mendapatkan penjelasan dari dokter yang bersangkutan. Dikarenakan jarak antara kasir dan bagian pemeriksaan penunjang cukup jauh, sebaiknya setelah diberikan form radiologi/laboratorium oleh dokter, pasien dapat langsung ke kasir untuk melakukan pembayaran dikarenakan kasir dan poliklinik lebih dekat. 


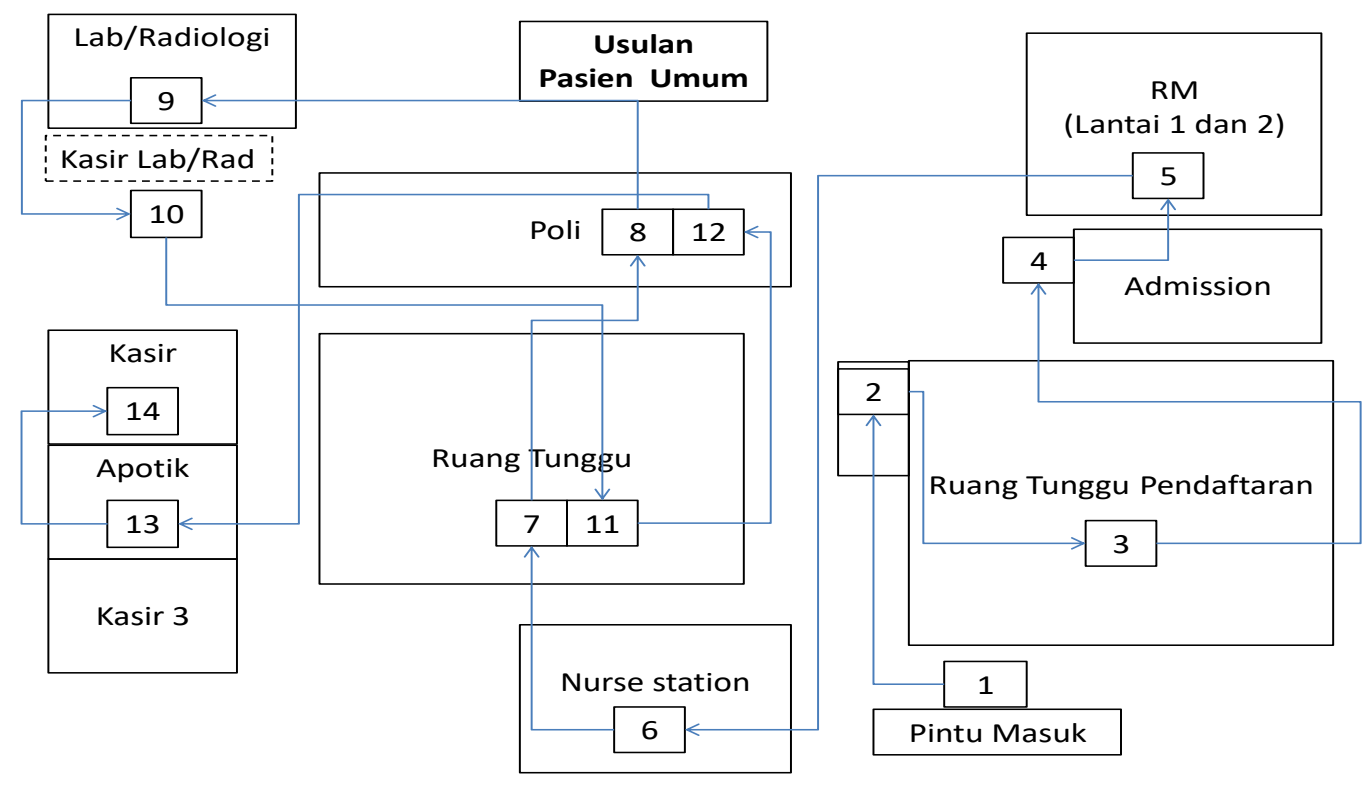

Gambar 5 Usulan Diagram Spaghetti

\section{Meninjau Kembali Waktu Praktek Dokter}

Mengatur waktu kerja dokter, terutama spesialis yang memerlukan tindakan dalam kegiatannya sehingga pasien tidak menunggu terlalu lama. Dalam hal ini dibedakan antara waktu dokter melakukan tindakan medis seperti bedah minor/mayor, pot operasi, dengan dokter yang melakukan konsultasi dengan pasien. Meninjau kembali perjanjian kerjasama dokter dengan rumah sakit untuk meningkatkan mutu pelayanan termasuk juga dengan dokter radiologi. Penataan kembali berkas rekam medis dan rak penyimpanannya. Tujuannya untuk mempermudah dalam pengambilan dan penyusunan kembali rekam medis pasien. Tentunya dengan rak dan penataan yang ergonomis. Di era saat ini banyak pasien yang lebih "memilih" untuk berobat, sehingga dengan adanya pelayanan pelanggan diharapkan dapat meningkatkan minat pasien untuk kembali berobat di RS Tugu Ibu.

\section{Memperbaiki System SIMRS dan EDP}

Dengan adanya sistem informasi yang terintegrasi di rumah sakit Tugu Ibu Depok maka pengelolaan administrasi pelayanan dimulai dari pendaftaran, pelayanan poliklinik, rekam medis sampai dengan penunjang medis lebih tertata 
dan lebih mudah, terutama untuk di bagian admission apabila menggunakan antrian digital tentunya mempermudah dalam berkomunikasi dengan pasien. Selain itu agar pasien tidak perlu lagi membawa-bawa berkas. Selain menggunakan sistem informasi yang terintegrasi tentu saja pencatatan secara manual juga diperlukan.

\section{PEMBAHASAN}

Value Assessment terhadap fisik dan fasilitas unit rawat jalan menilai tata letak, desain bangunan terhadap kemudahan pasien dalam mendapatkan pelayanan, keterjangkauan dibandingkan bentuk sebagaimana mestinya.

\section{Tabel 1. Fasilitas Unit Rawat Jalan}

\begin{tabular}{|c|c|c|}
\hline Fisik dan Bangunan & Ideal & Value Assessment \\
\hline $\begin{array}{l}\text { Ketika masuk lobby } \\
\text { jarak pintu masuk dan } \\
\text { pendaftaran terlalu } \\
\text { dekat dan ruang } \\
\text { tunggu terlalu sempit }\end{array}$ & $\begin{array}{l}\text { Ada lobby dan } \\
\text { tempat untuk } \\
\text { meletakkan } \\
\text { informasi kepada } \\
\text { pasien, ada meja } \\
\text { costumer service }\end{array}$ & $\begin{array}{l}\text { Ruangan terlalu crowded saat jam } \\
\text { sibuk, dan ruangan terlalu sempit. } \\
\text { Sehingga kadang pasien menunggu } \\
\text { antrian ke dokter sambil berdiri. Rumah } \\
\text { Sakit Tugu Ibu Depok tidak memiliki } \\
\text { Costumer Service }\end{array}$ \\
\hline $\begin{array}{l}\text { Rak penyimpanan } \\
\text { rekam medis terlalu } \\
\text { sempit dan tinggi }\end{array}$ & $\begin{array}{l}\text { Diantara rak } \\
\text { paling tidak dapat } \\
\text { dilalui } 2 \text { orang } \\
\text { petugas }\end{array}$ & $\begin{array}{l}\text { Rak terlalu tinggi, kurang ventilasi dan } \\
\text { pengap, penerangan kurang }\end{array}$ \\
\hline $\begin{array}{l}\text { Jumlah toilet terbatas } \\
\text { dan kotor serta berbau }\end{array}$ & $\begin{array}{l}\text { Toilet } \\
\text { diperbanyak dan } \\
\text { dibersihkan secara } \\
\text { berkala }\end{array}$ & $\begin{array}{l}\text { Dengan jumlah pasien } 400 \text { per hari } \\
\text { tentunya jumlah toilet masih sangat } \\
\text { kurang dan tim kebersihan outsourching } \\
\text { hanya membersihkan 1x sehari }\end{array}$ \\
\hline Letak Kasir & $\begin{array}{l}\text { Sebaiknya } \\
\text { disediakan kasir di } \\
\text { dekat } \\
\text { Laboratorium dan } \\
\text { Rontgent (di } \\
\text { belakang) }\end{array}$ & $\begin{array}{l}\text { Khususnya pasien umum yang harus } \\
\text { melakukan pemeriksaan penunjang, } \\
\text { jarak antara kasir dan lab/ro cukup jauh }\end{array}$ \\
\hline $\begin{array}{l}\text { Lahan parkir kurang } \\
\text { luas }\end{array}$ & $\begin{array}{l}\text { Lahan parkir lebih } \\
\text { luas }\end{array}$ & $\begin{array}{l}\text { Lahan parkir rumah sakit dipakai juga } \\
\text { oleh karyawan Mall yang berada di } \\
\text { sebelah Rumah Sakit }\end{array}$ \\
\hline
\end{tabular}

\section{Visual Management Assessment}

Merupakan alat bantu untuk menyampaikan informasi tanpa memerlukan bantuan dari pihak lain. 
Ayu Muthia, Ratna Atina Riandhini, Angsur Sudirja : Optimalisasi Upaya ...

Tabel 2. Visual Management Assessment

\begin{tabular}{|c|c|c|c|c|}
\hline Lokasi & $\begin{array}{l}\text { VM } \\
\text { Ada }\end{array}$ & $\begin{array}{c}\text { VM } \\
\text { Tidak } \\
\text { Ada }\end{array}$ & Bentuk VM & $\begin{array}{l}\text { Kebutuhan Akan } \\
\text { VM }\end{array}$ \\
\hline $\begin{array}{l}\text { Klasifikasi Pasien } \\
\text { loket pendaftaran }\end{array}$ & $\sqrt{ }$ & & $\begin{array}{l}\text { Sudah ada antrian khusus } \\
\text { pasien Umum dan BPJS }\end{array}$ & Tidak \\
\hline $\begin{array}{l}\text { Petunjuk alur proses } \\
\text { sesuai klasifikasi di } \\
\text { Lobby }\end{array}$ & $\sqrt{ }$ & & $\begin{array}{l}\text { Ada, namun berada di pojok } \\
\text { kanan dan kecil }\end{array}$ & $\begin{array}{l}\text { Perlu dilakukan } \\
\text { pemindahan }\end{array}$ \\
\hline Petunjuk arah Poli & & $\sqrt{ }$ & $\begin{array}{l}\text { Setiap poli diberi kode } \\
\text { Angka, dan sewaktu-waktu } \\
\text { dapat dipindah sesuai } \\
\text { dengan kebutuhan }\end{array}$ & $\begin{array}{l}\text { Membutuh-kan VM } \\
\text { tambahan }\end{array}$ \\
\hline $\begin{array}{l}\text { Petunjuk Ke Lab dan } \\
\text { Rongent }\end{array}$ & $\sqrt{ }$ & & Ada tapi tulisan terlalu kecil & $\begin{array}{l}\text { Membutuh-kan VM } \\
\text { tambahan }\end{array}$ \\
\hline
\end{tabular}

\section{Identifikasi 7 Waste}

Tabel 3. Tabel Identifikasi 7 Waste

\begin{tabular}{|c|c|c|c|}
\hline $\begin{array}{l}\text { Jenis Waste } \\
\text { (What) }\end{array}$ & $\begin{array}{l}\text { Sumber } \\
\text { Pemborosan } \\
\text { (Where) }\end{array}$ & $\begin{array}{l}\text { Waktu } \\
\text { Terjadinya } \\
\text { (When) }\end{array}$ & $\begin{array}{l}\text { Alasan Terjadinya } \\
\text { (Why) }\end{array}$ \\
\hline \multicolumn{4}{|l|}{ Delay (Penundaan) } \\
\hline $\begin{array}{l}\text { Pasien mengantri } 1 \\
\text { sampai } 2 \text { jam sebelum } \\
\text { loket pendaftaran dibuka } \\
\text { agar mendapatkan nomor } \\
\text { yang lebih awal }\end{array}$ & $\begin{array}{l}\text { Loket } \\
\text { Pendaftaran }\end{array}$ & $\begin{array}{l}\text { Proses } \\
\text { pendaftaran } \\
\text { pasien }\end{array}$ & $\begin{array}{l}\text { Belum adanya sistem pendaftaran } \\
\text { melalui whatsapp atau bbm, serta } \\
\text { tidak adanya sistem antrian by } \\
\text { phone }\end{array}$ \\
\hline $\begin{array}{l}\text { Menunggu klinik dimulai } \\
\text { pada pukul } 09.00 \text { dan } \\
15.00\end{array}$ & $\begin{array}{l}\text { Klinik rawat } \\
\text { jalan }\end{array}$ & $\begin{array}{l}\text { Proses } \\
\text { pelayanan }\end{array}$ & $\begin{array}{l}\text { Pasien mengambil nomor antrian } \\
\text { lebih awal dengan harapan dapat } \\
\text { segera mendapatkan pelayanan }\end{array}$ \\
\hline $\begin{array}{l}\text { Berkas RM yang sulit } \\
\text { ditemukan }\end{array}$ & $\begin{array}{l}\text { Ruang } \\
\text { penyimpanan } \\
\text { RM }\end{array}$ & $\begin{array}{l}\text { Proses } \\
\text { pencarian RM }\end{array}$ & $\begin{array}{l}\text { Petugas rekam medik masih } \\
\text { membutuhkan waktu untuk mencari } \\
\text { dan mengambil RM }\end{array}$ \\
\hline Dokter terlambat datang & $\begin{array}{l}\text { Klinik rawat } \\
\text { jalan }\end{array}$ & $\begin{array}{l}\text { Jam buka } \\
\text { poliklinik }\end{array}$ & $\begin{array}{l}\text { Terutama untuk dokter yang juga } \\
\text { melakukan tindakan operasi maka } \\
\text { butuh waktu lebih lama untuk } \\
\text { sampai di poliklinik }\end{array}$ \\
\hline \multicolumn{4}{|l|}{ Duplikasi } \\
\hline $\begin{array}{l}\text { Pasien lama tidak } \\
\text { membawa kartu berobat }\end{array}$ & $\begin{array}{l}\text { Loket } \\
\text { pendaftaran }\end{array}$ & $\begin{array}{l}\text { Selama proses } \\
\text { pendaftaran }\end{array}$ & $\begin{array}{l}\text { Petugas harus menanyakan kepada } \\
\text { pasien terlebih dahulu }\end{array}$ \\
\hline $\begin{array}{l}\text { Sistem computer yang } \\
\text { digunakan belum secara } \\
\text { otomatis menyimpan } \\
\text { data, tujuan, jenis } \\
\text { asuransi pasien }\end{array}$ & $\begin{array}{l}\text { Loket } \\
\text { pendaftaran }\end{array}$ & $\begin{array}{l}\text { Selama proses } \\
\text { pendaftaran }\end{array}$ & $\begin{array}{l}\text { Sewaktu petugas meng-entry data } \\
\text { harus buka tutup program data dan } \\
\text { print out nomor tracer }\end{array}$ \\
\hline $\begin{array}{l}\text { Pembayaran } \\
\text { menggunakan Swipe card } \\
\text { AdMedika sering offline }\end{array}$ & Kasir & $\begin{array}{l}\text { Proses } \\
\text { Pembayaran }\end{array}$ & $\begin{array}{l}\text { Penggunaan EDC dirasa sering } \\
\text { mengalami gangguan dibandingkan } \\
\text { pada saat menggunakan line } \\
\text { telepon }\end{array}$ \\
\hline \multicolumn{4}{|l|}{$\begin{array}{l}\text { Pergerakan yang tidak } \\
\text { perlu }\end{array}$} \\
\hline $\begin{array}{l}\text { Pasien JKN membawa- } \\
\text { bawa berkas }\end{array}$ & $\begin{array}{l}\text { Klinik Rawat } \\
\text { Jalan }\end{array}$ & $\begin{array}{l}\text { Proses rawat } \\
\text { jalan }\end{array}$ & $\begin{array}{l}\text { Bila EDP (Electronic Data } \\
\text { Processing) } \\
\text { sudah berjalan dengan }\end{array}$ \\
\hline
\end{tabular}


Jurnal Manajemen Kesehatan Yayasan RS.Dr.Soetomo Vol.6 No.1 April 2020 :

\begin{tabular}{|c|c|c|c|}
\hline $\begin{array}{l}\text { Jenis Waste } \\
\text { (What) }\end{array}$ & $\begin{array}{l}\text { Sumber } \\
\text { Pemborosan } \\
\text { (Where) }\end{array}$ & $\begin{array}{l}\text { Waktu } \\
\text { Terjadinya } \\
\text { (When) }\end{array}$ & $\begin{array}{l}\text { Alasan Terjadinya } \\
\text { (Why) }\end{array}$ \\
\hline & & berlangsung & $\begin{array}{l}\text { baik maka pasien tidak perlu } \\
\text { membawa-bawa berkas }\end{array}$ \\
\hline $\begin{array}{l}\text { Pasien umum berjalan } \\
\text { bolak balik untuk } \\
\text { menyerahkan form lab. } \\
\text { Dari poli ke } \\
\text { laboratorium/penunjang } \\
\text { lain, lalu ke kasir, } \\
\text { kembali a ke } \\
\text { laboratorium/penunjang } \\
\text { lain lagi untuk diambil } \\
\text { sample-nya }\end{array}$ & Kasir & $\begin{array}{l}\text { Selama proses } \\
\text { pembayaran }\end{array}$ & $\begin{array}{l}\text { Belum adanya kasir di instalasi } \\
\text { laboratorium/penunjang lain }\end{array}$ \\
\hline \multicolumn{4}{|l|}{ Defect } \\
\hline $\begin{array}{l}\text { Kesalahan } \\
\text { pengambilan RM }\end{array}$ & $\begin{array}{l}\text { Ruang } \\
\text { penyimpanan } \\
\text { RM }\end{array}$ & $\begin{array}{l}\text { Proses } \\
\text { penyimpanan } \\
\text { RM }\end{array}$ & $\begin{array}{l}\text { Petugas terburu-buru, kurang } \\
\text { detail dalam pencarian }\end{array}$ \\
\hline \multicolumn{4}{|l|}{ Communication } \\
\hline $\begin{array}{lr}\text { Pasien } & \text { baru } \\
\text { menanyakan } & \text { tempat } \\
\text { kepada petugas } & \end{array}$ & $\begin{array}{l}\text { Ruang } \\
\text { tunggu poli }\end{array}$ & $\begin{array}{l}\text { Saat pasien } \\
\text { akan atau } \\
\text { setelah } \\
\text { melakukan } \\
\text { pemeriksaan } \\
\text { penunjang }\end{array}$ & Kurangnya sarana petunjuk arah \\
\hline \multicolumn{4}{|l|}{ Inventory } \\
\hline $\begin{array}{l}\text { Satu pasien bisa } \\
\text { memiliki lebih dari } 1 \\
\text { RM dengan nomor RM } \\
\text { yang sama }\end{array}$ & $\begin{array}{l}\text { Ruang } \\
\text { penyimpanan } \\
\text { RM }\end{array}$ & $\begin{array}{l}\text { Proses } \\
\text { penyimpanan } \\
\text { RM }\end{array}$ & $\begin{array}{l}\text { Karena apabila pada saat } \\
\text { petugas sulit menemukan RM } \\
\text { pasien maka dibuatkan RM baru } \\
\text { dengan nomor yang sama }\end{array}$ \\
\hline \multicolumn{4}{|l|}{ Confussion } \\
\hline $\begin{array}{l}\text { Pasien berkerumun di } \\
\text { depan loket } \\
\text { pendaftaran }\end{array}$ & $\begin{array}{l}\text { Loket } \\
\text { Pendaftaran }\end{array}$ & $\begin{array}{l}\text { Proses } \\
\text { pendaftaran }\end{array}$ & $\begin{array}{l}\text { Kurang informasi mengenai } \\
\text { aturan tata cara pendaftaran }\end{array}$ \\
\hline
\end{tabular}

Berdasarkan hasil penelitian dapat disimpulkan bahwa hasil Value Assessment pasien mulai dari proses pendaftaran hingga mendapatkan obat di apotik masih menunjukan wasting time yang terlalu lama. Menunggu nomor antrian average 10,5 menit, menunggu untuk bertemu dokter average 82,5 menit dan cycle time average 46,5 menit untuk Berjalan ke Laboratorium atau Radiologi, ke kasir (untuk pasien umum), kembali lagi ke Laboratorium atau Radiologi, menunggu hasil keluar dan kembali lagi ke dokter. (Total Non Value Added 139,5 menit). Hal ini terjadi karena banyaknya hambatan-hambatan yang terjadi sepanjang alur proses pelayanan unit rawat jalan. Hasil identifikasi 
Ayu Muthia, Ratna Atina Riandhini, Angsur Sudirja : Optimalisasi Upaya ...

kegiatan dan aktivitas selama proses kerja unit rawat jalan yang ada banyak ditemukan pemobrosan (waste), sehingga rasio aktivitas yang bernilai tambah (Value Added Activities) ada yang kurang dari 30\%, sebagai bentuk masalah pada manusia / man yaitu dokter Radiologi yang tidak full time sehingga hasil penunjang lama, belum adanya costumer service, skill beberapa tenaga perawat dirasa kurang, perawat berada di dua ruangan poli sekaligus, dokter yang terlambat dan petugas Rekam Medik banyak yang belum ikut pelatihan Rekam Medik. Sedangkan dalam methode ditemukan bahwa masih adanya error dalam swipe card di Admission tapi over limit di kasir, alur rawat jalan pasien belum baku terutama dari segi administrasi, adanya berkas "titipan" untuk perawat rawat jalan, belum adanya pemanfaatan media sosial dan pendaftaran melalui telepon.

Untuk machine yaitu EDC's Swipe card yang sering mengalami offline, EDP kurang, line error, hang berjam-jam serta SIMRS yang belum maksimal. Pada environment, ditemukan bahwa toilet kurang jumlah dan kurang bersih serta licin, kurangnya informasi tentang petunjuk arah, baik brupa banner, gambar ataupun tulisan-tulisan di lingkungan rumah sakit (visual management) serta area parkir yang masih kurang. Usulan perbaikan dengan menganalisis akar penyebab masalah, membuat langkah-langkah perbaikan dengan memperkirakan kemampuan rumah sakit dan faktor-faktor yang mempengaruhinya. Perbaikan yang diusulkan terbagi menjadi 3 tahap yaitu; jangka pendek, menengah dan panjang. Kriteria perbaikan jangka pendek diimplementasikan bila dalam pelaksanaannya diperkirakan tidak membutuhkan biaya.

Kriteria perbaikan jangka menengah dipilih bila dalam pelaksanaannya membutuhkan biaya dan sarana tambahan, sedangkan perbaikan jangka panjang bila dalam pelaksanaannya diperkirakan membutuhkan biaya, sarana dan perubaha kebijakan dari pimpinan institusi. Sehingga diperlukannya penerapan lean hospital untuk menghilangkan dan meminimalkan pemborosan sebagai bentuk perbaikan dan peningkatan pelayanan di unit rawat jalan. Pada admission ditemukan Dokter dan perawat sudah siap di klinik namun status rekam medis pasien ada yang belum diantar ke nurse station. Klinik-klinik tertentu yang dokternya terlambat datang (biasanya terjadi pada dokter dengan tindakan). Pasien 
menunggu lebih lama bila pasien sebelumnya dilakukan tindakan. Belum optimalnya pencatatan di buku inventaris dan logbook mengenai seberapa sering peralatan dipakai belum ada. Terutama pada pasien umum, karena setelah menyerahkan surat pengantar untuk pemeriksaan penunjang, pasien diminta untuk membayar pemeriksaan tersebut di kasir, kembali lagi ke ruang laboratorium/radiologi untuk menyerahkan bukti bayar, baru dilakukan pemeriksaan dan mengambil hasilnya. Bila hasil laboratorium yang dibutuhkan maka pasien kembali ke ruang poli untuk menyerahkan hasil laboratorium kepada dokter sebelumnya. Tapi bila hasil radiologi diambil keesokan harinya menunggu dokter radiologi membaca hasil rontgen. Di sini pasien melakukan gerakan berjalan dari ruang penunjang ke kasir, kembali ke ruang penunjang, kemudian ke poliklinik, ditambah dengan waktu tunggu.

Pasien JKN dan jaminan membawa-bawa SEP dan surat jaminan sehingga resiko untuk tertinggal dan hilang sangat besar. Dokter radiologi tidak full time sehingga pasien lama mendapatkan hasil. EDP kurang, kadang hang berjam-jam sehingga pelayanan pasien terhambat, koreksi status pasien juga sering terjadi. Hasil wawancara pasien umum tidak beranggapan jarak antar ruang labolatorium dan radiologi dengan ruang poliklinik berjauhan karena masih dalam area rumah sakit hasil pemeriksaannya dapat diambil pada hari itu juga, namun bagi pasien baru dan umum yang belum terbiasa akan merasa jaraknya jauh karena alur proses pelayanan harus membayar ke kasir kemudian menyerahkan tanda bukti pembayaran, dilakukan pemeriksaan lalu menunggu lagi untuk mengambil hasil pemeriksaan.

\section{SIMPULAN}

Berdasarkan hasil penelitian dapat disimpulkan bahwa hasil Value Assessment pasien mulai dari proses pendaftaran hingga mendapatkan obat di apotik masih menunjukan wasting time yang terlalu lama yaitu total Non Value Added 139,5 menit. Hal ini terjadi karena banyaknya hambatan-hambatan yang terjadi sepanjang alur proses pelayanan unit rawat jalan. Hasil identifikasi kegiatan dan aktivitas selama proses kerja unit rawat jalan yang ada banyak ditemukan pemoborosan (waste), sehingga rasio aktivitas yang bernilai tambah 
Ayu Muthia, Ratna Atina Riandhini, Angsur Sudirja : Optimalisasi Upaya ...

(Value Added Activities) ada yang kurang dari 30\%. Kriteria perbaikan jangka pendek diimplementasikan bila dalam pelaksanaannya diperkirakan tidak membutuhkan biaya. Kriteria perbaikan jangka menengah dipilih bila dalam pelaksanaannya membutuhkan biaya dan sarana tambahan, sedangkan perbaikan jangka panjang bila dalam pelaksanaannya diperkirakan membutuhkan biaya, sarana dan perubahan kebijakan dari pimpinan institusi.

\section{UCAPAN TERIMA KASIH}

Ucapan Terima Kasih kepada Direktur Rumah Sakit Tugu Ibu Depok dr. Syaifuddin, MARS, kepada semua pihak yang telah memberikan bantuan dalam penyelesaian penelitian ini, terutama kepada Dr. drg. Wahyu Sulistiadi, MARS, Drs. Heru Kusumanto, MBA., MARS, drg. Sri Rahayu, MMR., Ph.D dan Sumijatun, S.Kp., MARS., Ph.D, atas kontribusinya yang besar sehingga penelitian ini dapat terlaksana dengan baik.

\section{DAFTAR PUSTAKA}

Astion, M. L., Zanganeh-Kamooshi, S., Xu, M., Rutledge, J. C., Simpson, J., Huang, H., \& Heim, J. (2012). A medium sized lab solving complex problems by collaborating with a local academic industrial engineering group that emphasizes math modeling. Clinical Chemistry.

Ben-Tovim, D. I., Bassham, J. E., Bolch, D., Martin, M. A., Dougherty, M., \& Szwarcbord, M. (2007). Lean thinking across a hospital: redesigning care at the Flinders Medical Centre. Australian Health Review : A Publication of the Australian Hospital Association. https://doi.org/10.1071/AH070010

Faisal, S. (1990). Penelitian Kualitatif, Dasar Dan Aplikasi. In Yayasan Asih Asah Asuh.

Gaspersz. (2011). Lean Six Sigma for Manufacturing and Service Industries. Gramedia.

Hines, P., Holwe, M., \& Rich, N. (2004). Learning to evolve: A review of contemporary lean thinking. In International Journal of Operations and Production Management. https://doi.org/10.1108/01443570410558049

Iswanto, A. H. (2015). Hospital Efficiency and Data Envelopment Analysis (DEA): An Empirical Analysis of Kemang Medical Care (KMC). SSRN Electronic Journal. https://doi.org/10.2139/ssrn.2629898

L'Hommedieu, T., \& Kappeler, K. (2010). Lean methodology in i.v. medication processes in a children's hospital. American Journal of Health-System Pharmacy. https://doi.org/10.2146/ajhp100151

Lash, S. (2009). Lean Hospitals: Improving Quality, Patient Safety, and Employee Satisfaction. AORN Journal. https://doi.org/10.1016/s0001-2092(09)00184-7

Lean and Six Sigma: A practical guide for clinicians and managers. (2010). International Journal

of

Care

Pathways. 
Jurnal Manajemen Kesehatan Yayasan RS.Dr.Soetomo Vol.6 No.1 April 2020 :

https://doi.org/10.1258/jicp.2009.009017

Stainback, S., \& Stainback, W. (1984). Methodological Considerations in Qualitative Research. Journal of the Association for Persons with Severe Handicaps. https://doi.org/10.1177/154079698400900407

\begin{tabular}{|l|l|}
\hline Submission & 14 Maret 2020 \\
\hline Review & 17 Maret 2020 \\
\hline Accept & 07 April 2020 \\
\hline Publish & 23 April 2020 \\
\hline DOI & $10.29241 / j m k . v \%$ vi\%i.312 \\
\hline Sinta Level & 4 (Empat) \\
\hline
\end{tabular}

